\title{
Processing Method for Yield Monitoring Signal of Impulse Type Grain Flow Sensor
}

\author{
Li Wang ${ }^{\text {a }}$ Zhaohua Wang \\ Department of Energy Engineering, Yulin University, Yulin 719000, Shaanxi, China \\ a278116312@qq.com
}

Keywords: impulse type, grain, flow sensor, signal processing

\begin{abstract}
The grain yield monitoring plays a crucial role in the practice of fine agriculture. This paper will use indoor calibration bench of impulse type grain flow sensor, rely on frequency converter to simulate working condition of combine harvester in the field. It will analyze the yield monitoring signal processing method of the impulse type grain flow sensor, in hope for providing a reference for the industry.
\end{abstract}

\section{Introduction}

At this stage, devices used in grain yield monitoring are photo plethysmography, ray-based, weighing, and impulse type in the main types of yield monitoring. In such yield monitoring devices, impulse type grain flow sensor has been widely used due to its low cost and reliable work. In practical applications, background noise can affect the yield monitoring accuracy.

\section{Test device}

The impulse type grain flow sensor adopted in this paper is the two-plate differential impulse type grain flow sensor. The measuring board and the reference board have basically the same structure and are arranged in parallel. The indoor calibration test bench of impulse type grain flow sensor includes signal conditioning circuit, industrial computer, inverter and other parts. The speed sensor for the elevator is a Hall-type proximity switch. The frequency measurement can be completed by detecting the sprocket teeth, and the speed can be measured by the PCI-1780U timer card.

\section{The yield monitoring signal processing of impulse type grain flow sensor}

\subsection{Signal acquisition}

In signal acquisition, the associated sampling frequency of the combine harvester is shown in Table 1.

Table 1 related sampling frequency setting of combine harvester engine

\begin{tabular}{cc}
\hline Name & Sampling frequency \\
\hline Output signal of reference board and & $3 \mathrm{kHz}$ \\
measurement board & \\
Granary quality information & $40 \mathrm{~Hz}$ \\
lift conveyer speed & $0.25 \mathrm{~s}$ \\
\hline
\end{tabular}

Combined with Table 1, under normal circumstances, engine rated speed of combine harvester is 2200r / min. Using arithmetic mean filtering, it can be confirmed that the update frequency of quality information is $4 \mathrm{~Hz}$ [1]. In its no-load operation, signal conditioning circuits on the measurement board and reference board can be adjusted, so that the two output signals are consistent. After no-load analysis, it is found that there are random noise and background noise in the output signal of the 
reference plate and the measuring plate of impulse type grain flow sensor. At $50 \mathrm{~Hz}$, the output signal is shown in Figure 1.

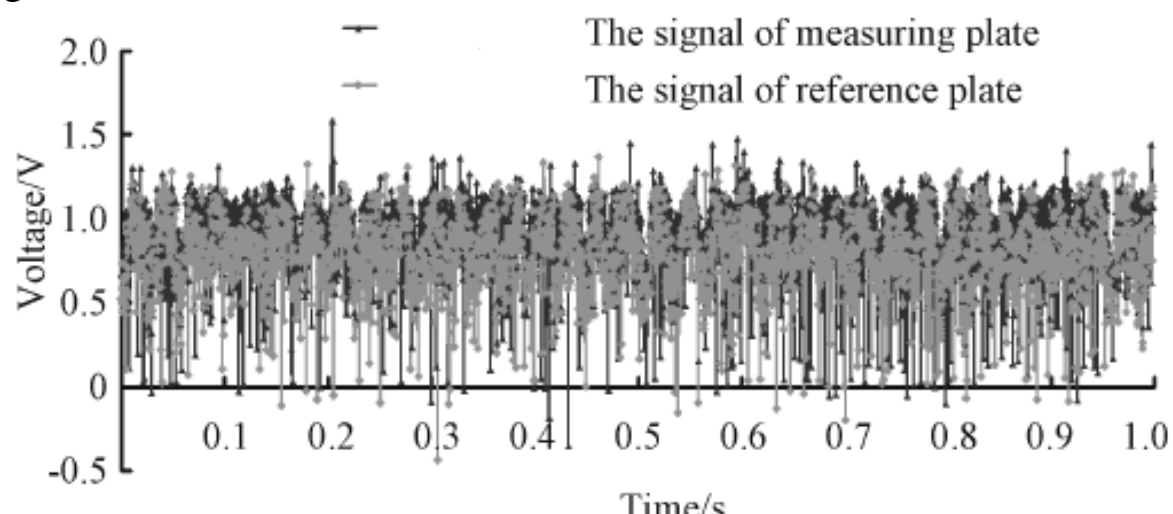

Time/s

Fig. 1 output signal of the measurement board and reference board acquired synchronously at $50 \mathrm{~Hz}$

Combined with Figure 1, we can see that the noise is relatively large.

\subsection{Signal preprocessing}

By using arithmetic mean filtering, find the average of every 10 samples and output the measured value. The detection frequency of output signal on the measuring board and reference board decrease to $300 \mathrm{~Hz}$. The output signal after filtered by the arithmetic mean is Fig.2.

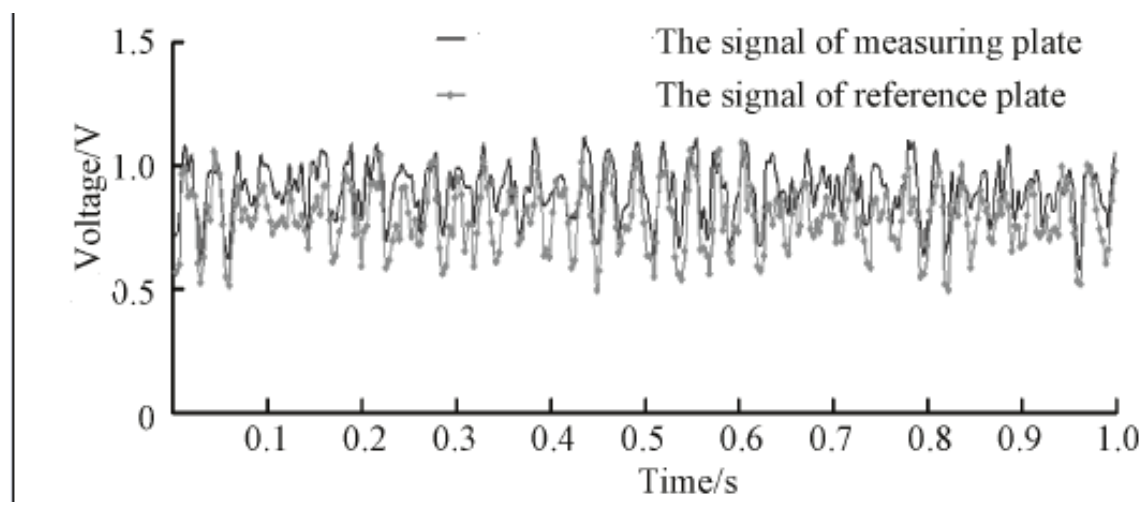

Fig. 2 Output signal diagram of measurement board and reference board after filtered by the arithmetic average

Combined with Figure 2, after filtered by the arithmetic mean, we can find that random noise has been reduced, and the trend of the two signals are basically the same.

\subsection{Eliminate background noise}

Carry out time-domain differential processing on filter the output signal. The test bench runs at no load. The output signals of the reference board and measurement board are background noise. After the difference, the result should be close to zero. However, the output signal is still not fully synchronized, and the signal amplitude of the time-domain differential result greatly changes. Therefore, it can be considered that the culling effect is not good and the statistical analysis is performed. The signal mean value is $0.119 \mathrm{~V}$ and the signal standard deviation is $0.082 \mathrm{~V}$. Carry out 300 points of Discrete Fourier Transform (DFT) and then make frequency-domain difference on DFT results. Perform 300 points of inverse discrete Fourier transform (IDFT) again and make statistical analysis of the differential output signal in frequency domain. It shows that the mean value of the signal is $0.119 \mathrm{~V}$, the difference is $0.047 \mathrm{~V}$, the signal fluctuation is relatively small, and the rejection effect is better than the former. The specific effect is shown in Figure 3. 


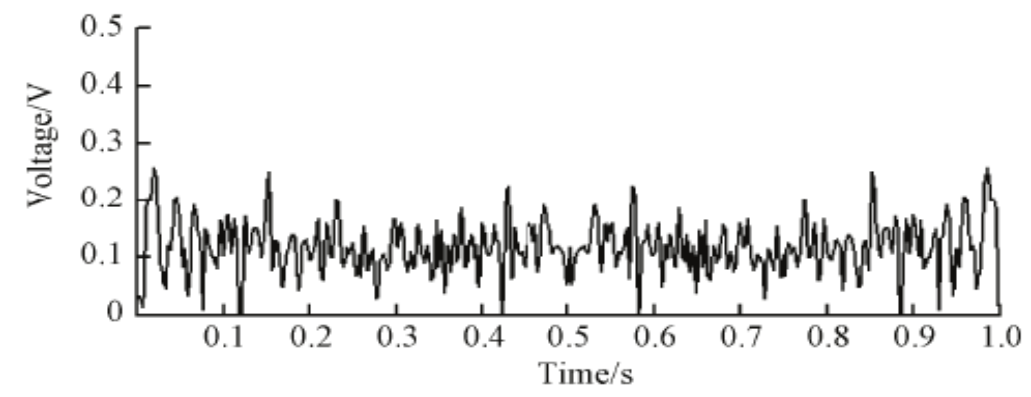

Fig. 3 Frequency domain difference results of filter output signal on measurement plate and reference plate

During no-load operation, the output frequency of the frequency converter is stable between $20 \mathrm{~Hz}$ and $35 \mathrm{~Hz}$. By carrying out according to program that signal averaging filter preprocessing $\rightarrow$ discrete Fourier transform $\rightarrow$ frequency domain difference $\rightarrow$ inverse discrete Fourier transform, the sensor output signal is obtained. After analysis of the output results, it is found that the frequency-domain differential processing method has a stable background noise rejection effect under different working conditions [2].

\subsection{Second arithmetic mean filter}

In order to further eliminate the background noise, the output signal of the sensor needs to be subjected to the second arithmetic average filtering. Every 75 sensor output signal, find the average and output measurement value. The second arithmetic mean filter output is the final yield monitoring output signal. The signal frequency is $4 \mathrm{~Hz}$. The results shown in Table 2.

Table 2 Second arithmetic average filter results

\begin{tabular}{lll}
\hline $\begin{array}{l}\text { Yield monitoring output signal average of } \\
\text { the second arithmetic mean filter }\end{array}$ & $\begin{array}{l}\text { Yield monitoring signal standard } \\
\text { deviation of } \\
\text { Second arithmetic mean filter }\end{array}$ & \\
\hline $0.121 \mathrm{~V}$ & $0.008 \mathrm{~V}$ & \\
\hline
\end{tabular}

Combined with Table 2, we can see that the background noise is relatively weak at this time. To achieve zero calibration, we need to reduce $0.119 \mathrm{~V}$ in the output signal.

\subsection{Practical application}

Make tests on indoor bench calibration of yield monitoring sensor, test results at $20,30 \mathrm{~Hz}$ is shown in Table 3.

Table 3 Test results at 20, 30hz

\begin{tabular}{ccccc}
\hline $\begin{array}{c}\text { Serial } \\
\text { number }\end{array}$ & $\begin{array}{c}\text { Motor operating } \\
\text { frequency }(\mathrm{Hz})\end{array}$ & $\begin{array}{c}\text { Line speed of lift } \\
\text { conveyer(m·s-1) }\end{array}$ & $\begin{array}{c}\text { Grain seeds } \\
\text { flow }(\mathrm{kg} \cdot \mathrm{s}-1)\end{array}$ & $\begin{array}{c}\text { Yield } \\
\text { monitoring } \\
\text { output signal } \\
(\mathrm{V})\end{array}$ \\
\hline 1 & 30 & 0.56 & 0.3527 & 0.6555 \\
2 & & & 0.6012 & 0.5136 \\
3 & & & 1.1636 & 0.5625 \\
4 & & & 1.3165 & 0.5765 \\
5 & 30 & 0.26 & 1.6365 & 0.6165 \\
1 & & & 0.3051 & 0.5316 \\
2 & & & 0.2660 & 0.5752 \\
3 & & & 1.3516 & 0.6352 \\
4 & & & 1.6055 & 0.6575 \\
5 & & & 3.0761 & 0.5626 \\
\hline
\end{tabular}

The test results at $40,50 \mathrm{~Hz}$ is shown in Table 4 below. 
Table 4 Test results at $40,50 \mathrm{hz}$

\begin{tabular}{ccccc}
\hline $\begin{array}{c}\text { Serial } \\
\text { number }\end{array}$ & $\begin{array}{c}\text { Motor operating } \\
\text { frequency }(\mathrm{Hz})\end{array}$ & $\begin{array}{c}\text { Line speed of lift } \\
\text { conveyer(m·s-1) }\end{array}$ & $\begin{array}{c}\text { Grain seeds } \\
\text { flow }(\mathrm{kg} \cdot \mathrm{s}-1)\end{array}$ & $\begin{array}{c}\text { Yield } \\
\text { monitoring } \\
\text { output signal } \\
(\mathrm{V})\end{array}$ \\
\hline 1 & 60 & 1.13 & 0.3277 & 0.6075 \\
2 & & & 1.3566 & 0.6763 \\
3 & & & 1.5210 & 0.5352 \\
4 & & & 3.0536 & 0.2076 \\
5 & \multirow{2}{*}{50} & & 3.3251 & 0.7356 \\
1 & & & 0.3255 & 0.6665 \\
2 & & & 1.1565 & 0.5602 \\
3 & & & 1.5633 & 0.2165 \\
4 & & & 3.0013 & 0.2636 \\
5 & & & 3.3172 & 0.7556 \\
\hline
\end{tabular}

According to test results of table 4 and table 5, we can find that the calibration equation meets the practical application requirements. The output power of variable frequency speed controller is now set to $37 \mathrm{~Hz}$ and $45 \mathrm{~Hz}$, and the indoor simulation test is carried out on it. In the experiment, different grain flow rate can be obtained by changing the opening degree of the flapper, the measurement of the grain flow rate is performed, and the error is calculated to obtain the result, as shown in Table 6.

Table 6 Test results of indoor simulation for yield monitoring

\begin{tabular}{ccccc}
\hline $\begin{array}{c}\text { Serial } \\
\text { number }\end{array}$ & $\begin{array}{c}\text { Motor } \\
\text { operating } \\
\text { frequency } \\
(\mathrm{Hz})\end{array}$ & $\begin{array}{c}\text { Output signal } \\
\text { of yield } \\
\text { monitoring( } \\
\mathrm{V})\end{array}$ & $\begin{array}{c}\text { Calculate grain } \\
\text { seed flow } \\
(\mathrm{kg} \cdot \mathrm{s}-1)\end{array}$ & $\begin{array}{c}\text { Measure grain flow } \\
(\mathrm{kg} \cdot \mathrm{s}-1)\end{array}$ \\
\hline 1 & 35 & 0.6616 & 0.71 & 0.70 \\
2 & & 0.5 & 1.66 & 1.63 \\
3 & & 0.557 & 1.71 & 1.73 \\
4 & & 0.2261 & 3.30 & 3.32 \\
1 & 60 & 0.6702 & 0.73 & 0.70 \\
2 & & 0.5503 & 1.66 & 1.63 \\
3 & & 0.2303 & 1.72 & 3.30 \\
4 & & 0.762 & 3.35 & 3.75 \\
\hline
\end{tabular}

Combining Table 6, the linear velocity of lift conveyer is $1.04 \mathrm{~m} \cdot \mathrm{s}-1$ at $37 \mathrm{~Hz}$ and the linear velocity of lift conveyer is $1.26 \mathrm{~m} \cdot \mathrm{s}-1$ at $45 \mathrm{~Hz}$. After calculating them, the maximum relative error is found to be $3.1 \%$, which can judge that this method is effective.

\section{Conclusions}

In summary, the discrete Fourier transformation is made on the reference board output signal to extract the spectral characteristics of the background vibration noise. Frequency domain difference is made on DFT results of the reference board and the measurement board output signal to remove background vibration noise from the measurement board output signal. This frequency-domain difference method has a good signal processing effect for the two-plate differential impulse type grain flow sensor. 


\section{References}

[1] Shoji K, Miyamoto M. Improving the accuracy of estimating grain weight by discriminating each grain impact on the yield sensor[J]. Precision Agriculture, 2014, 15(1):31-43.

[2] Zhou J, Cong B, Liu C. Elimination of vibration noise from an impact-type grain mass flow sensor[J]. Precision Agriculture, 2014, 15(6):627-638.

[3] Kanno Y, Yasuda K, Fujita K, et al. Robustness of SDOF elastoplastic structure subjected to double-impulse input under simultaneous uncertainties of yield deformation and stiffness[J]. International Journal of Non-Linear Mechanics, 2017, 91:151-162.

[4] Lyle G, Bryan B A, Ostendorf B. Post-processing methods to eliminate erroneous grain yield measurements: review and directions for future development[J]. Precision Agriculture, 2014, 15(4):377-402.

[5] Ali S T, Sivaraman V, Ostry D. Eliminating Reconciliation Cost in Secret Key Generation for Body-Worn Health Monitoring Devices[J]. IEEE Transactions on Mobile Computing, 2014, 13(12):2763-2776. 